\title{
Study on the Spatial-Temporal Pattern Evolution and Countermeasures of Regional Coordinated Development in Anhui Province, China
}

\author{
Yizhen Zhang ${ }^{1,2 *}$, Weidong Cao ${ }^{1,2}$, Kun Zhang3 \\ ${ }^{1}$ School of Geography and Tourism, Anhui Normal University, Wuhu, China \\ ${ }^{2}$ Urban and Regional Planning Research Center of Anhui Normal University, Wuhu, China \\ ${ }^{3}$ College of Tourism, Huaqiao University, Quanzhou, China \\ Email: `zyzdzwan@163.com, kunzhang1996@163.com
}

How to cite this paper: Zhang, Y. Z., Cao, W. D., \& Zhang, K. (2020). Study on the Spatial-Temporal Pattern Evolution and Countermeasures of Regional Coordinated Development in Anhui Province, China. Current Urban Studies, 8, 115-128. https://doi.org/10.4236/cus.2020.81005

Received: March 2, 2020

Accepted: March 27, 2020

Published: March 30, 2020

Copyright $\odot 2020$ by author(s) and Scientific Research Publishing Inc. This work is licensed under the Creative Commons Attribution International License (CC BY 4.0)

http://creativecommons.org/licenses/by/4.0/

\section{(c) (i) Open Access}

\begin{abstract}
Regional coordinated development was an important measure to resolve new contradictions in the new era, and it has gradually become a hotspot in geography research. At three time points of 2010,2013, and 2017, by constructing an evaluation index system for the city comprehensive competitiveness, the entropy method and the coupling coordination model were used to study the coordinated development pattern of cities in Anhui Province. Moreover, we tried to raise the issue of regional coordinated development in Anhui Province and corresponding countermeasures. The results showed that the comprehensive competitiveness of cities in Anhui Province has strong spatiotemporal heterogeneity. The spatial development pattern with Hefei as the core was more obvious. The degree of urban coupling in Anhui Province first declined and then increased. The high values of coupling degree were mainly concentrated in cities such as Hefei and Chuzhou, and the low values were mainly concentrated in cities in northern Anhui such as Bozhou and Suzhou. Moreover, the degree of city coordination in Anhui Province has strong hierarchical characteristics. Hefei, Chuzhou and Bengbu have always occupied the position of high-quality coordination, while Chizhou, Bozhou and Suzhou in southern Anhui and northern Anhui have been in a state of imbalance. The research was conducive to improving the relevant theories of regional coordinated development and to provide more theoretical basis and practical significance for the coordinated development of Anhui Province.
\end{abstract}

\section{Keywords}

Coordinated Development, Coupling, Spatiotemporal Pattern, Anhui 
Province, China

\section{Introduction}

Regional coordinated development refers to the healthy and orderly development of environmental, economic and social factors in an open system (Xu \& $\mathrm{Wu}, 2010)$. Meanwhile, it is also an inevitable choice to adapt to the sustainable development of the new era and an important embodiment of high-level economic and social development (Song \& Wu, 2010). However, differences in resource, location advantages, and transportation between cities have led to greater spatial and temporal heterogeneity in regional development levels (Lan \& Zhong, 2018). Moreover, the consolidation of regional industrial division of labor and development paths has intensified the imbalance of spatial development (Li \& Wang, 2016). The purpose of coordinated regional development is to bring into play the comparative advantages and enthusiasm of different regions, and gradually reduce the gap in regional development through the improvement of market mechanisms, cooperation mechanisms, mutual assistance mechanisms, and support mechanisms to form a new pattern of complementary advantages and coordinated development among different regions (Xie et al., 2016). From the beginning of the Ninth Five-Year Plan, China has implemented a series of major strategies to promote coordinated regional development, including the rise of the central region and the development of the western region. Moreover, Anhui Province has been accelerating the realization of regional comprehensive and coordinated development through measures such as the implementation of the strategy of rural rejuvenation and integration of the development of the Yangtze River Delta.

There are currently two main streams of regional coordinated development research. The first concerns the influencing factors of coordinated development research. Lan et al. studied the main factors affecting the coordinated development of metropolitan economy and logistics (Lan \& Zhong, 2018). Wei et al. studied the regional development differences of Jiangsu Province from 1950 to 1995 and believed that human capital, physical capital, and institutional structure were the main factors that caused regional development differences (Wei \& Kim, 2002). Moreover, economic, ecological environment, and local government actions as well as innovation capacity, are also considered to affect regional coordinated development (Yang et al., 2014; Xu et al., 2011).

The second stream focuses on the research perspective of coordinated regional development. Some scholars found that although the environment-tourismeconomy system in western Hunan, China failed to achieve a high-yield index, the degree of coupling between subsystems and the coordinated development index showed an overall upward trend (Yuan et al., 2014). Other scholars measured the coordinated development of the economy, society, and environment of 
Hubei Province through the coordinated development model, and believed that Hubei performed poorly in coordinated development (Ding et al., 2014). Moreover, some scholars have also studied regional coordinated development from the perspectives of industry, innovation, and development policy (Lester \& Reckhow, 2013; Pastor et al., 2010; Ralphs et al., 2020).

The above research has laid a deep foundation for this research. Since the reform and opening up, China has experienced an evolution from a balanced development to an unbalanced development strategy, and has gradually adjusted to a comprehensive and coordinated development strategy (Ploberger, 2016). At present, the integration of the Yangtze River Delta has become a national strategy. However, Anhui Province's low level of development in the Yangtze River Delta is not conducive to the integrated development of the Yangtze River Delta, and even severely restricts the comprehensive and coordinated development of our economy and industry. Hence, it is very important to strengthen the research on the coordinated development of Anhui Province and provide relevant policy suggestions for promoting Anhui's full integration into the Yangtze River Delta integrated development. However, since the integration of the Yangtze River Delta into a national strategy, scholars have rarely studied the regional coordinated development pattern of Anhui Province by constructing an indicator system.

To fill those gaps, this article attempts to study the pattern of urban coordinated development in Anhui Province by constructing an indicator system of coordinated urban development and applying methods such as entropy and coupling coordination models. Moreover, we reveal the development differences between cities, and try to give corresponding countermeasures to their existing problems, with a view to providing suggestions for regional coordinated development in Anhui Province.

The remainder of this paper was organized as follows. Section 2 presents the study area, data sources, and research methods. Section 3 the entropy method and coupling coordination model were used to explore the evolution of the spatial and temporal pattern of Anhui's comprehensive competitiveness and coupling coordination degree. Section 4 summarizes the conclusions and a try to raise existing problems and corresponding countermeasures.

\section{Data and Methods}

\subsection{Study Area}

As shown in Figure 1, Anhui jurisdiction over 16 prefecture-level cities including Hefei, Suzhou, Huaibei, Chuhou, Fuyang, Bengbu, Huainan, Bozhou, Luan, Maanshan, Anqing, Wuhu, Tongling, Xuancheng, Chizhou, and Huangshan. At the end of 2018, Anhui has a permanent population of 62.548 million people, a GDP of 2779.9 billion yuan, a rapid economic development, and great development potential. Meanwhile, there were also practical problems of small economic development scale and large regional development differences. For example, at 


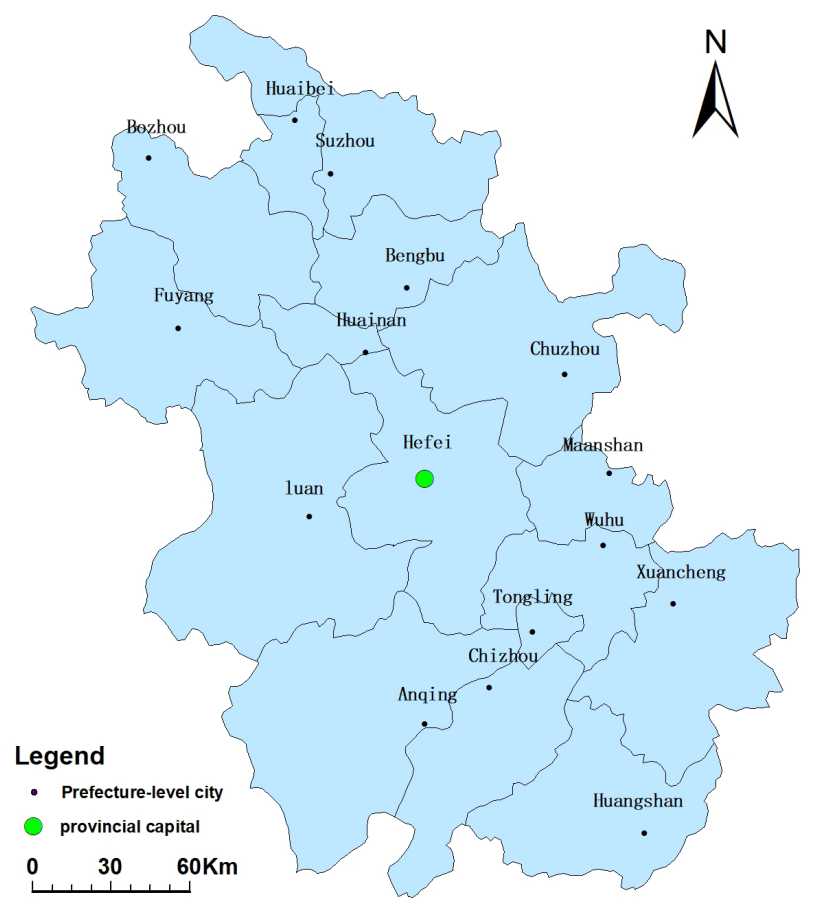

Figure 1. Study area of Anhui province.

the end of 2018, Hefei's GDP accounted for $26.21 \%$ of the province's total, while most of the cities in southern and northern Anhui had smaller economic volumes and lower levels of development. The approval of the "Yangtze River Delta Urban Agglomeration Development Plan" and the "Central Plain Urban Agglomeration Development Plan" in 2016 greatly enhanced the strategic position of Anhui Province in the national economic development, and the overall development of Anhui Province was exposed to unprecedented opportunities (Miao et al., 2016).

\subsection{Data Sources}

According to the latest administrative divisions of Anhui Province, taking 16 prefecture-level cities in Anhui as the research area, and rationally collecting and processing relevant data such as population, GDP, and fiscal revenue of each city in 2010, 2013, and 2017 in accordance with scientific principles. The data mainly come from the statistical yearbooks of prefecture-level cities such as the Statistical Yearbook of Hefei, Statistical Yearbook of Wuhu, and Statistical Yearbook of Bengbu.

\subsection{Research Methods}

\subsubsection{Construction of Urban Comprehensive Competitiveness Index System}

With reference to relevant literature (Zhang et al., 2015), and combined with the actual development of Anhui, select the social competitiveness, economic competitiveness, scientific and technological competitiveness, and transportation 
competitiveness to build an index system for comprehensive urban competitiveness evaluation. Among them, social development competitiveness includes total household income, the number of employed persons in the tertiary industry, and the number of permanent residents. Economic competitiveness includes gross domestic product (GDP), fiscal revenue, and total investment. Scientific and technological competitiveness includes the number of universities, the number of invention patents, and the investment in scientific research funds. Transportation competitiveness includes total passenger transportation, total freight transportation, and highway mileage. The specific index classification criteria are shown in Table 1.

\subsubsection{Data Standardization and Weight Setting}

Because the dimensions of the data are different, in order to facilitate the calculation and elimination of the impact of different dimensions on the data, the data was dimensionlessly processed. Compared with the traditional analytic hierarchy process, principal component analysis, etc., the entropy method is an objective weighting method, which avoids the bias caused by human factors and has higher credibility and accuracy (Huang et al., 2017).

Positive indicator:

$$
X_{i j}^{\prime}=\left(\max \left\{X_{j}\right\}-X_{i j}\right) /\left(\max \left\{X_{j}\right\}-\min \left\{X_{j}\right\}\right) \times 100
$$

Reverse indicator:

$$
X_{i j}^{\prime}=\left(X_{i j}-\min \left\{X_{j}\right\}\right) /\left(\max \left\{X_{j}\right\}-\min \left\{X_{j}\right\}\right) \times 100
$$

$X_{i j}^{\prime}$ and $X_{i j}$ in the formula represent the normalized value and the original value, respect tively. In order to reflect the maximum possible representation of the data, this study used the entropy method to determine the weight of the data. The calculation steps are as follows.

Table 1. The index system and weight of urban comprehensive competitiveness.

\begin{tabular}{cllc}
\hline Target layer & \multicolumn{1}{c}{ Subsystem layer } & \multicolumn{1}{c}{ Indicator layer } & Weights \\
\hline & A Social competitiveness & A1 Total household income & 0.0573 \\
& & A2 Tertiary employment & 0.0688 \\
Urban & B Economic competitiveness & A3Permanent residents & 0.0538 \\
$\begin{array}{c}\text { comprehensive } \\
\text { competitiveness }\end{array}$ & & B1 Gross domestic product & 0.0890 \\
index system & C Technological competitiveness & C2 Patent & 0.0871 \\
& & B3 Total investment & 0.1156 \\
& & C1 Research funding & 0.1236 \\
& & D1 Total passenger traffic & 0.0493 \\
& D Transportation competitiveness & D2 Total freight & 0.1090 \\
& & D3 Highway mileage & 0.0342 \\
\hline
\end{tabular}


The Formulas (1) and (2) are used to standardize each index, and the proportion of the $j$-th evaluation index in the $i$-th evaluation object was (Zhang et al., 2015).

$$
S_{i j}=x_{i j} / \sum_{j=1}^{m}(1 \leq j \leq m)
$$

Calculate the entropy $h_{j}$ of the $j$-th index:

$$
h_{j}=-\frac{1}{\ln m} \sum_{j=1}^{m} S_{i j} \ln S_{i j}
$$

Calculate the difference $a_{j}$ according to the entropy $h_{j}$ :

$$
a_{j}=1-h_{i}
$$

Calculate indicator weight $w_{j}$ :

$$
w_{j}=a_{j} / \sum_{j=1}^{p} a_{j}
$$

The calculation results are shown in Table 1.

\subsubsection{Coupling Model}

$$
C=\left[\frac{S \times E \times T \times J}{\left(\frac{S+E+T+J}{4}\right)^{4}}\right]^{4}
$$

The coupling coordination model was used to analyze the level of coordinated development of things. Coupling degree refers to the interaction and influence between two or more systems, and realizes the dynamic relationship of coordinated development, which can reflect the degree of interdependence and restriction between systems (Gong, 2013). In the formula, $S, E, T$, and $J$ respectively represent the competitiveness of social development, the competitiveness of economic development, the competitiveness of scientific and technological development, and the competitiveness of transportation development. $C$ represents the degree of coupling. The greater $C$ is, the greater the coupling of urban development will be.

\subsubsection{Coordination Model}

Although the coupling model can reflect the correlation of the development of various elements within the city, it cannot reflect the coordination of the overall development of the city (Song \& Wu, 2010). The degree of coordination refers to the degree of benign coupling in the coupling interaction relationship, and it can reflect the quality of coordination. Hence, this study used the coordination model to measure the coordination of urban development.

$$
D=\sqrt{C \times(S+E+T+J)}
$$

In the formula, $S, E, T$, and $J$ respectively represent the competitiveness of 
social development, the competitiveness of economic development, the competitiveness of scientific and technological development, and the competitiveness of transportation development. $D$ represents the coordination of urban development. The greater $D$ is, the greater the coordination of urban development will be.

\section{Results}

\subsection{Evolution of the Space-Time Pattern of Comprehensive Competitiveness}

As shown in Figure 2, we observed that the evolution of the spatial-temporal pattern of the comprehensive competitiveness of cities in Anhui Province. From the perspective of time, the comprehensive competitiveness of Hefei in 2010, 2013 and 2017 was 14.6 times 17.7 times 27.4 times higher than the last ranked Chizhou. Obviously, with the passage of time, the comprehensive competitiveness of Hefei has been expanding. From the perspective of space, the comprehensive competitiveness of Hefei, Wuhu and Fuyang ranked top three in 2010, 2013 and 2017, and Fuyang has a growing trend. It may be because with the process of urbanization, Fuyang has exerted its huge demographic dividend. It was worth noting that, Chizhou's comprehensive competitiveness has been at a very low level, which may be related to its too small population base, relatively simple industry, and outflow of population. However, Luan, located in the Dabie Mountains in southern Anhui, may be due to inconvenient transportation and weak external links, and its overall competitiveness has continued to decline significantly. Moreover, the comprehensive competitiveness index of most cities in the province was low, the degree of activity was weak, and the fluctuation was not large. On the whole, the comprehensive competitiveness of cities in Anhui Province has strong spatiotemporal heterogeneity. The spatial development pattern with Hefei as the core was more obvious.

The results were shown in Figure 3, the trend analysis tools in ArcGIS10.2 were used to analyze the comprehensive competitiveness of different cities in Anhui in different years through the analysis of longitude and latitude in geographic space. The trend of comprehensive competitiveness of Anhui Province

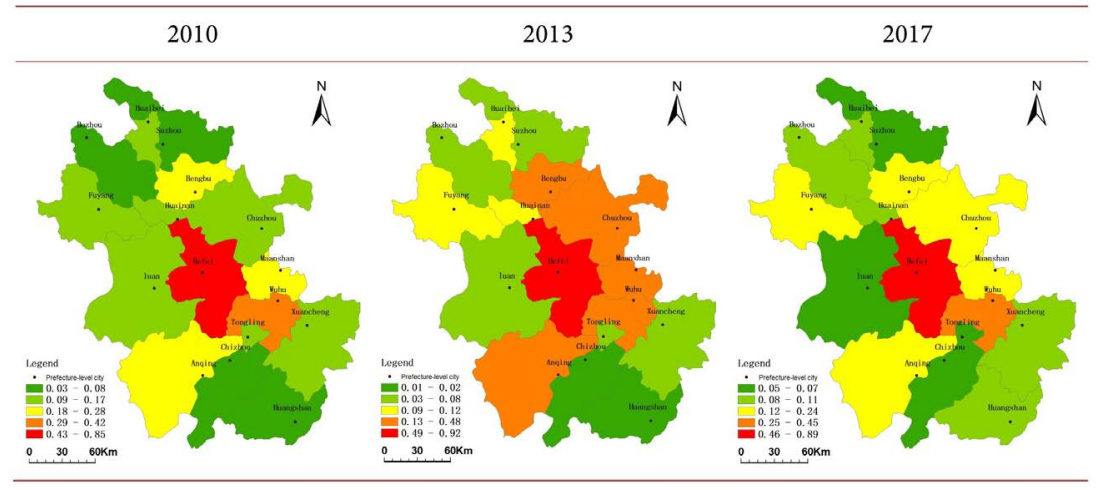

Figure 2. Urban competitiveness in 2010-2013-2017. 


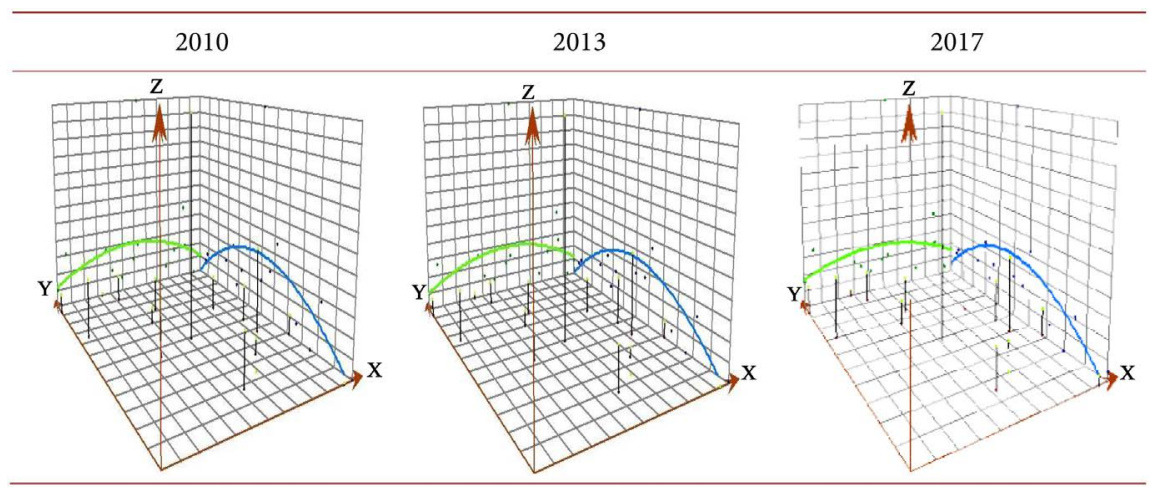

Figure 3. Trend analysis of comprehensive competitiveness from 2010-2013-2017.

can be summarized as: middle high and low on both sides. This finding was consistent with the actual development of Anhui Province. In the future, it was necessary to strengthen the development of cities such as Suzhou in northern Anhui, Huangshan and Chizhou in southern Anhui and promote the comprehensive and coordinated development of Anhui Province.

\subsection{Spatiotemporal Evolution of Coupling Degree}

As shown in Figure 4, the coupling degree of coordinated development in Anhui Province has obvious spatial and temporal heterogeneity. The coupling degree of coordinated development of Hefei maintained high levels in 2010, 2013, and 2017, which were $0.83,0.89$, and 0.85 , respectively. Moreover, we observed that the coordinated development coupling of Chuzhou maintained a high level in 2010, 2013, and 2017 which were $0.63,0.75$, and 0.70 , respectively. It may be because Chuzhou was the core city of Nanjing Metropolis and Hefei Metropolis. The economic and industrial spillover effects of Hefei and Nanjing bring long-term benefits to the development of Chuzhou. However, in sharp contrast to this was Bozhou in northern Anhui. From 2010 to 2017, the coupling degree of coordinated development in Bozhou was lower than 0.01, which indicates that the coupling degree of social, economic, technological and transportation development in Bozhou was relatively low. Overall, he high values of coupling in Anhui Province were mainly concentrated in cities such as Hefei and Chuzhou, while the low values were mainly concentrated in cities in southern Anhui Chizhou, Huangshan, northern Anhui Bozhou, and Suzhou. It was not difficult to find that the industrial structure of the cities in southern and northern Anhui was relatively single, and the regional industrial division of labor and development path was relatively solidified. In the future, it was necessary to further adjust the industrial structure and guide the healthy and sustainable development of economic industries.

\subsection{Evolution of the Spatiotemporal Pattern of Coordination}

As shown in Figure 5, the degree of coordinated development of cities in Anhui Province showed a significant difference in time and space. In 2010, 2013 and 


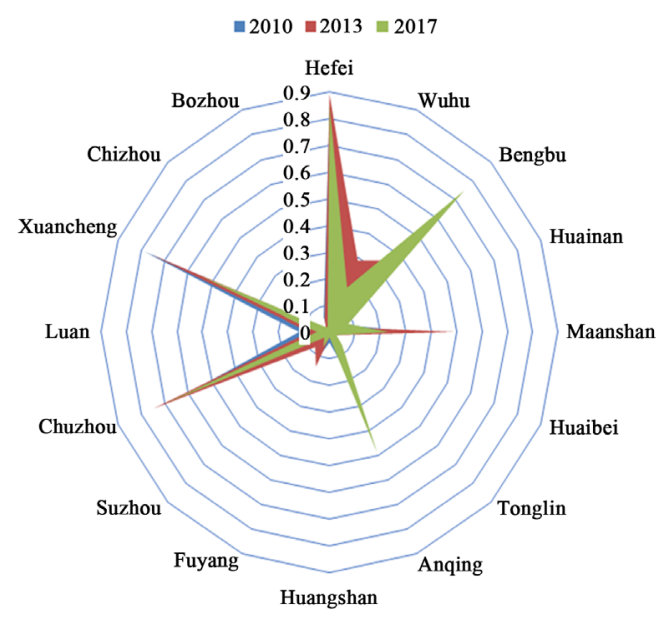

Figure 4. Urban coupling degree of Anhui Province, 2010-2013-2017.

(2010 A

Figure 5. Urban coordination degree 2010-2013-2017.

2017, Hefei was the city with the highest coordination degree, with coordination degrees of $0.377,0.490$ and 0.440 respectively. As the provincial capital of Anhui, Hefei has better resources, location and transportation advantages. Especially in recent years, as the process of urbanization has accelerated its economic and industrial development, the level of coordinated urban development has also gradually increased. Moreover, the degree of coordinated development of Anqing increased from 0.155 in 2010 to 0.296 in 2015, showing a continuous upward trend. However, the degree of coordinated development of Xuancheng dropped from 0.346 in 2010 to 0.177 in 2017, showing a sharp decline. The degree of coordinated development of Bozhou and Suzhou in northern Anhui in 2010, 2013, and 2017 was generally low, all below 0.04 . The industrial structure of Bozhou and Suzhou in the north of Anhui was relatively single, the level of economic development was low, and the population loss was serious, which was the main reason leading to the low level of coordinated development of cities. Overall, the high values of coordinated development have been concentrated in cities such as Chuzhou, Hefei, and Bengbu, while cities in Chizhou, Huangshan in southern Anhui and Bozhou and Suzhou in northern Anhui have been in low-value zones. 
According to the original research and the actual situation of Anhui Province (Xu et al., 2011), the level and classification criteria of the coordination degree were set, as shown in Table 2. From 2010 to 2017, the cities with First level coordination mainly concentrated in Hefei and Bengbu Chuzhou; the secondary coordination was mainly represented by cities such as Maanshan, Wuhu, Anqing. However, cities in southern and northern Anhui, such as Chizhou and Bozhou, have been at a low level of coordinated development. Overall, the degree of urban coupling and coordination in Anhui Province was generally on the rise, but there were also some phenomena in which the city's development was slow and the degree of coordination was decreasing.

\section{Conclusion and Discussion}

\subsection{Conclusions}

In this study, by constructing an evaluation index system of urban comprehensive competitiveness, using entropy method and coupling coordination model to study the coordinated development pattern of cities in Anhui Province in 2010, 2013 and 2017, and try to raise existing problems and corresponding countermeasures. Research showed that the comprehensive competitiveness of cities in Anhui Province has strong spatial and temporal heterogeneity. From 2010 to 2017, Hefei's comprehensive competitiveness was the highest in the province. It further highlights Hefei's position as the only core city in Anhui Province. Moreover, the degree of change in the degree of coupling and coordination of cities in Anhui Province was relatively small. High values of coupling and coordination are mainly concentrated in cities such as Hefei and Chuzhou, and low

Table 2. Grades of urban coordination in 2010-2013-2017.

\begin{tabular}{|c|c|c|c|c|}
\hline \multirow{3}{*}{$\begin{array}{l}\text { Coordination } \\
\text { value }\end{array}$} & \multirow{3}{*}{$\begin{array}{c}\text { Coordination } \\
\text { level }\end{array}$} & \multicolumn{3}{|c|}{ City } \\
\hline & & \multicolumn{3}{|c|}{ Years } \\
\hline & & 2010 & 2013 & 2017 \\
\hline $0.301-0.490$ & $\begin{array}{c}\text { First level } \\
\text { coordination }\end{array}$ & $\begin{array}{l}\text { Hefei Bengbu } \\
\text { Xuancheng } \\
\text { Chuzhou }\end{array}$ & $\begin{array}{c}\text { Hefei } \\
\text { Xuancheng } \\
\text { Chuzhou Bengbu } \\
\text { Maanshan }\end{array}$ & $\begin{array}{c}\text { Hefei } \\
\text { Chuzhou } \\
\text { Bengbu }\end{array}$ \\
\hline $0.180-0.300$ & $\begin{array}{l}\text { Secondary } \\
\text { coordination }\end{array}$ & Maanshan & Wuhu Anqing & Maanshan \\
\hline $0.120-0.179$ & $\begin{array}{l}\text { Three-level } \\
\text { coordination }\end{array}$ & $\begin{array}{l}\text { Huaibei Wuhu } \\
\text { Tongling Anqing }\end{array}$ & Tongling & $\begin{array}{l}\text { Huaibei Wuhu } \\
\text { Luan Huainan } \\
\text { Xuancheng }\end{array}$ \\
\hline $0.066-0.119$ & $\begin{array}{l}\text { Four-level } \\
\text { coordination }\end{array}$ & $\begin{array}{c}\text { Huainan } \\
\text { Huangshan }\end{array}$ & $\begin{array}{c}\text { Huaibei } \\
\text { Huainan Luan }\end{array}$ & Fuyang \\
\hline $0.030-0.065$ & $\begin{array}{c}\text { Five-level } \\
\text { coordination }\end{array}$ & Fuyang Luan & $\begin{array}{l}\text { Fuyang } \\
\text { Chizhou }\end{array}$ & $\begin{array}{l}\text { Suzhou } \\
\text { Chizhou }\end{array}$ \\
\hline$<0.030$ & $\begin{array}{c}\text { Six-level } \\
\text { coordination }\end{array}$ & $\begin{array}{c}\text { Bozhou Suzhou } \\
\text { Chizhou }\end{array}$ & $\begin{array}{c}\text { Bozhou } \\
\text { Huangshan } \\
\text { Suzhou }\end{array}$ & $\begin{array}{l}\text { Bozhou } \\
\text { Huangshan } \\
\text { Tongling }\end{array}$ \\
\hline
\end{tabular}


values were mainly concentrated in cities such as Chizhou and Bozhou. It shows that the degree of coupling and coordination of cities in Anhui Province has obvious hierarchical characteristics. In the future, it was necessary to strengthen the development of cities such as Bozhou and Suzhou in northern Anhui, Huangshan and Chizhou in southern Anhui and promote the comprehensive and coordinated development of Anhui Province. Furthermore, according to the current research situation, we found that Anhui Province has a lot to do in promoting regional coordinated development. Hence, this study proposes that Anhui should actively participate in the integrated development of the Yangtze River Delta, establish a unified and coordinated development mechanism at the provincial level, and take advantage of the comparative advantages of industrial resources in various cities.

\subsection{Discussion}

\subsubsection{Actively Participate in the Integrated Development of the Yangtze River Delta}

Anhui Province was located in the eastern part of China and has obvious geographical advantages. It plays a role of supporting east and west in the whole development pattern of the country. In 2018, the integration of the Yangtze River Delta became a national strategy. All cities in Anhui should fully seize this strategic opportunity and actively use their own advantages to actively integrate into the integrated development of the Yangtze River Delta. Northern Anhui should actively build a leading development zone centered on Bengbu, integrate the advantageous resources of northern Anhui cities, and promote the integrated development of cities such as Fuyang, Chenzhou, Huainan, and Suzhou. South Anhui should take Wuhu as the center and the Yangtze River as the development belt to drive Anqing, Tongling, Xuancheng, Chizhou, Huangshan and other cities to achieve coordinated development (Miao et al., 2016). Secondly, with the unique geographical advantages of Hefei and the comprehensive strength of science and technology, culture, and economy, the overall development of Anhui Province was driven. Finally, recognize the comparative advantages, development potentials, and resource advantages of each city to better position the city's functions, define development goals, and fully integrate into the integrated development of the Yangtze River Delta.

\subsubsection{Establish a Unified and Coordinated Development Mechanism at the Provincial Level}

The unified and coordinated development of Anhui Province was a strategic goal dominated by the national and provincial levels in the new period, and a key step to eliminate new contradictions in the new era. In the past, due to the city's hierarchy, historical factors, and policy factors, it was difficult to establish a normalized dialogue platform mechanism between cities, which easily caused unequal rights to dialogue everywhere (Adam et al., 2018; Wei \& Kim, 2002). Hence, the establishment and actual implementation of the coordination mech- 
anism at the provincial level was of great significance. This mechanism not only needs to coordinate more detailed issues between the provincial and municipal levels, but also needs to analyze specific issues. Moreover, according to the specific conditions of each city, each department should strengthen communication, carefully negotiate, take into account the interests of all parties, coordinate contradictions among all parties, and coordinate overall development. Policy makers should also consider the huge differences in the development of cities from a practical perspective. For example, underdeveloped regions should receive more policy support and make full use of the "tangible hands" to achieve coordinated regional development.

\subsubsection{Give Full Play to the Advantages of Industrial Resources in Each City and Actively Deepen Industrial Reform}

With the development of urbanization, a large number of people have migrated to central cities, and the provincial capital Hefei has gathered a large number of talents, funds, and enterprises. However, other cities in Anhui Province have smaller industries and weaker agglomeration capabilities. Hence, Anhui Province should give full play to the comparative advantages of various cities and actively explore new bright spots in urban industries. For cities in northern Anhui that rely heavily on the "coal economy", industrial transformation should be accelerated and new industries and new factors introduced. Meanwhile, establish a strategic vision and carry out scientific and technological research and development while undertaking the transfer of industries. Hefei should mainly focus on high-tech industries, finance and cutting-edge manufacturing, and strive to build a national comprehensive science and technology city. Wuhu should actively move towards the direction of robotics, new energy, and aerospace to realize the diversification of industries and promote the balanced development of urban industries. The cities of Huangshan, Chizhou, and Luan in southern Anhui mainly rely on scenic resources such as Huangshan, Jiuhua, and Dabie Mountains, and gradually realize the transition from the "small tourism" to the "big tourism" era. Moreover, the province should give full play to the industrial cooperation and dialogue platform, fully respect the interests of all parties, coordinate contradictions, negotiate and negotiate on an equal footing, and strive to create a new and comprehensive development of Anhui in the new era.

\section{Conflicts of Interest}

The author declares no conflicts of interest regarding the publication of this paper.

\section{References}

Adam, P. H., Sue, E. H., \& Nigel, G. (2018). Build Two-Way Rapport for Better Policymaking. Nature, 556, 174-174. https://doi.org/10.1038/d41586-018-04167-4

Ding, Y., de Vries, B., \& Han, Q. (2014). Measuring Regional Sustainability by a Coordinated Development Model of Economy, Society, and Environment: A Case Study of 
Hubei Province. Procedia Environmental Sciences, 22, 131-137. https://doi.org/10.1016/j.proenv.2014.11.013

Gong, S. Y. (2013). Study on the Coupled Coordination Degrees between Urban Land in Tensive Use System and Social Economic Development: A Case of Shandong Province. In Advanced Materials Research (Vol. 726, pp. 4827-4830). New York: Trans Tech Publications Ltd. https://doi.org/10.4028/www.scientific.net/AMR.726-731.4827

Huang, L., Zhao, W., Xie, G., Xie, H., \& Yi, Q. (2017). Evaluating and Optimizing city E-Commerce Competitiveness Based on FA-CA Model: A Case from 32 Cities in China. Revista de la Facultad de Ingenieria, 32, 298-308.

Lan, S. L., \& Zhong, R. Y. (2018). Coordinated Development between Metropolitan Economy and Logistics for Sustainability. Resources, Conservation and Recycling, 128, 345-354. https://doi.org/10.1016/j.resconrec.2016.08.017

Lester, T. W., \& Reckhow, S. (2013). Network Governance and Regional Equity: Shared Agendas or Problematic Partners? Planning Theory, 12, 115-138. https://doi.org/10.1177/1473095212455189

Li, N., \& Wang, K. F. (2016). Evaluation of Coordinated Development of Regional Resources and Economy around Shandong Peninsula Urban Agglomerations. Journal of Groundwater Science and Engineering, 4, 220-228.

Miao, C. L., Sun, L. Y., \& Yang, L. (2016). The Studies of Ecological Environmental Quality Assessment in Anhui Province Based on Ecological Footprint. Ecological Indicators, 60, 879-883. https://doi.org/10.1016/j.ecolind.2015.08.040

Pastor, M., Benner, C., \& Matsuoka, M. (2011). For What It's Worth: Regional Equity, Community Organizing, and Metropolitan America. Community Development, 42, 437-457. https://doi.org/10.1080/15575330.2010.532877

Ploberger, C. (2016). China's Reform and Opening Process: A New Model of Political Economy? Journal of Chinese Economic and Business Studies, 14, 69-87. https://doi.org/10.1080/14765284.2015.1132933

Ralphs, E., Shahab, S., \& Ahmadpoor, N. (2020). Access to Small Airports and the Impact on Regional Growth in the UK. Current Urban Studies, 8, 24-56. https://doi.org/10.4236/cus.2020.81002

Song, J. B., \& Wu, C. Y. (2010). The Study on Evaluation of Coordinated Development between Urbanization and Ecological Environment among City Cluster in the Yangtze River Delta. China Soft Science, 2, 78-87.

Wei, Y. D., \& Kim, S. (2002). Widening Inter-County Inequality in Jiangsu Province, China, 1950-95. Journal of Development Studies, 38, 142-164. https://doi.org/10.1080/00220380412331322621

Wu, X., Cao, F., \& Liu, F. (2007). The Position and Spatial Development Strategy of Anhui Province in the Urban Agglomeration of the Yangtze River Delta. Urban Studies, 6.

Xie, M., Wang, J., \& Chen, K. (2016). Coordinated Development Analysis of the "Resources-Environment-Ecology-Economy-Society" Complex System in China. Sustainability, 8, 582. https://doi.org/10.3390/su8060582

Xu, Y. Z., \& Wu, H. M. (2010). Empirical Study on the Comprehensive Efficiency of the Level of Regional Coordinated Development Considering Environmental Factors. China Industrial Economics, 8, 34-44.

Xu, Y., Wang, Y., \& Lin, Y. (2011). Research on Coupling Coordinated Degree Valuation of Regional Sci-Tech Innovation and Sci-Tech Finance. Science of Science and Management of $S . \& T, 12,116-122$. 
Yang, Q., Ding, Y., De Vries, B., Han, Q., \& Ma, H. (2014). Assessing Regional Sustainability Using a Model of Coordinated Development Index: A Case Study of Mainland China. Sustainability, 6, 9282-9304. https://doi.org/10.3390/su6085231

Yuan, Y., Jin, M., Ren, J., Hu, M., \& Ren, P. (2014). The Dynamic Coordinated Development of a Regional Environment-Tourism-Economy System: A Case Study from Western Hunan Province, China. Sustainability, 6, 5231-5251.

Zhang, W., Deng, F., \& Liang, X. (2015). Comprehensive Evaluation of Urban Competitiveness in Chengdu Based on Factor Analysis. In Proceedings of the Ninth International Conference on Management Science and Engineering Management (pp. 1433-1440). Berlin, Heidelberg: Springer.

https://doi.org/10.1007/978-3-662-47241-5_119 